\title{
La ley de financiamiento educativo En la Argentina una lucha histórica
}

Sonia Alesso*

RESUMEN: El artículo presenta una serie de análisis enfocados en los alcances que tuvo de la ley vigente en estos diez años; las características y planteos centrales del nuevo proyecto; y los desafíos de la Confederación de Trabajadores de la Educación de la República Argentina (Ctera) en el contexto de un proyecto de país gobernado bajo las directrices de la restauración conservadora.

Palabras clave: Ley de financiamiento educativo. Nuevo proyecto educativo. La restauración conservadora en educación.

\section{Presentación}

$\mathrm{P}$ oder incidir en la definición de políticas públicas que reivindiquen los derechos de los trabajadores y garanticen el derecho social a la educación ha sido, sin sudas, uno de los principales objetivos históricos de la Confederación de Trabajadores de la Educación de la República Argentina (Ctera).

Hay hitos y hechos fundamentales en los últimos años que demuestran haber alcanzado dicho objetivo, que se ven plasmado en la aprobación de una Ley Nacional de Financiamiento Educativo junto a la derogación de la Ley Federal y la creación de una nueva Ley de Educación Nacional.

Estas leyes reflejan, en gran medida, la concreción de todo un proceso de lucha, de resistencia y de proposición que emprendió Ctera, con total decisión, desde el histórico ayuno de la Carpa Blanca, poniendo en debate público la necesidad perentoria de que 
el Estado Nacional volviera a responsabilizarse de la educación e invirtiera sustancialmente en todo el sistema, dejando de ser un mero administrador y gestor de programas focalizados que se limitaba a gerenciar el financiamiento proveniente de los organismos internacionales de crédito, que, a cambio, ponían las condiciones del ajuste, la flexibilización y la precarización laboral.

En los años de resistencia organizada frente a los embates de políticas neoliberales comenzamos a forjar el camino que llevaba progresivamente al Estado Nacional a responsabilizarse en el financiamiento educativo aportando a las provincias a través del Fondo Nacional de Incentivo Docente (Fonid).

Desde aquel logro histórico, la Ctera no cesó de luchar y continuó en la consolidación de una correlación de fuerza que, paulatinamente, permitió seguir avanzando hasta llegar, en el año 2005, a la sanción de la Ley de Financiamiento Educativo nº 26.075, que permitió alcanzar otro conjunto de propósitos ya más ambiciosos que los que podíamos plantearnos en los años 90. Esta ley contribuyó sustancialmente a garantizar el derecho social a la educación con políticas de inclusión y a mejorar las condiciones de enseñanza y de aprendizaje especialmente para los sectores que habían quedado marginados del sistema en tiempos del capitalismo salvaje.

Más allá de aquellos importantes avances, fundamentalmente del cumplimiento, en el año 2010, de la meta global de llegar al 6\% del PBI para la inversión educativa, hoy se renuevan los desafíos y se amplían los horizontes para dar la batalla por el derecho a la educación pública, popular y de calidad.

El hecho de haber logrado la sanción de una nueva Ley de Educación Nacional que no sólo define a la Educación como un derecho, sino que además amplía la cantidad de años de escolaridad obligatoria, generando más responsabilidad para el Estado, conmina a redefinir un nuevo presupuesto, más importante que el establecido hace diez años, para que se puedan concretar los nuevos desafíos, como así también los puntos que aún quedan pendientes y por cumplir en la Argentina.

A diez años de la sanción de la Ley de Financiamiento Educativo nํㅜ 26.075, la Ctera plantea la necesidad de una revisión y redefinición del tema para que la inversión esté a la altura de los requerimientos, llevando la misma al 10\% del PBI.

El desafío hoy se redobla, ya que nuestra batalla se despliega en un contexto en el que las políticas neoliberales y neoconservadoras implementadas por el actual Gobierno Nacional están llevando nuevamente a la Argentina al endeudamiento externo y al pago de lo que, de manera inmoral, hoy nos exigen los llamados "fondos buitre".

Desde Ctera estamos convencidos que este nuevo endeudamiento y los pagos de capital y de intereses usurarios a los organismos internacionales de crédito condicionarán las posibilidades de atender a la necesidad de una mayor inversión educativa, la defensa de los puestos de trabajo y de nuestra soberanía nacional. 
Desde este posicionamiento, la Ctera acompañó la propuesta de un proyecto de Ley que fuera elaborado por la Diputa Nacional Adriana Puiggrós y que se presentara en el Congreso Nacional en el mes de noviembre de 2015 para su tratamiento. Hoy nos encontramos en plena campaña para que este proyecto sea Ley, a los efectos que se pueda cumplir con lo que la educación pública, popular y democrática necesita en nuestro país.

En el presente artículo, vamos a presentar una serie de análisis enfocados en tres puntos que nos parecen centrales: a) los alcances que tuvo de la ley vigente en estos diez años; b) las características y planteos centrales del nuevo proyecto presentado y, por último, c) los desafíos de nuestra organización en el contexto de un proyecto de país gobernado bajo las directrices de la restauración conservadora.

\section{Avances y asuntos pendientes de la Ley n⿳⺈ 26.075, de 2005}

Para referirnos a los alcances vamos a considerar la relatividad de los mismos ya que cualquier valoración que se haga va a resultar completa o incompleta de acuerdo a los parámetros de análisis que se decidan considerar. Al respecto hay una verdad relativa, tanto en los números a tener en cuenta como en el impacto político-educativo que cada sector le pueda asignar al alcance de esta ley.

De todos modos, la importancia de esta normativa está ya en el hecho de haber sido sancionada como tal, porque si bien desde los orígenes de la legislación argentina se estableció la obligatoriedad de la educación y, por lo tanto la responsabilidad del Estado como garante de su financiamiento, fue recién en el año 2005, durante el gobierno de Néstor Kirchner, que se pudo contar con un marco normativo que fijaba las metas, instrumentos y responsabilidades respectivas para garantizar el derecho social a la educación.

Es ese marco, desde Ctera siempre hemos considerado como una gran conquista el hecho de, después de tantas luchas, haber logrado la sanción de una ley de este tipo en la que se planteaba como meta llevar la inversión educativa al 6\% del PBI. Y un triunfo aún mayor, lograr que esa meta no quede sólo en el terreno del discurso sino que se plasme en la realidad concreta consiguiendo que en el año 2010 se cumpla esa meta global llegando sobradamente a dicho porcentaje $(6,47 \%)$.

Un dato de la realidad que puede condicionar la veracidad de la afirmación del "cumplimiento del 6\%" es el hecho del cambio realizado en la fórmula para calcular el PBI. Con ese nuevo cálculo, hoy se estima que la inversión en educación ha llegado al 5,3 \% del PBI. De todos modos, lo que resulta indudable es el significativo crecimiento del financiamiento educativo, aun punto tal, que en estos años se da "el mayor nivel de inversión por alumno del que se tenga registro histórico"1.

Incluso, en términos comparativos a nivel mundial, la inversión fue tan importante que Argentina ${ }^{2}$ quedó como el séptimo país (entre los 108 países relevados por 
la UNESCO) que más avanzó en inversión educativa. Ocupando además, el segundo lugar en América Latina, con un 64\% de aumento en la inversión entre el 2004 y el 2011, luego de Uruguay que registra un aumento del $80 \%$ en el mismo período; aunque ese esfuerzo de Uruguay le permitió recién llegar al 4,5 \% del PBI en 2011.

Este cumplimiento de la meta global del $6 \%$ del PBI ha permitido avanzar con la ampliación de la cobertura, especialmente en el nivel inicial y en la educación secundaria y en aquellas provincias que habían estado históricamente postergadas como las del Noreste y del Noroeste argentino.

El otro punto importante del alcance de esta Ley puede observarse en el proceso progresivo de recomposición salarial de los trabajadores de la educación de todo el país, como así también en la ampliación de las plantas orgánicas funcionales de las escuelas y en la creación de nuevos cargos y horas cátedra en los diversos niveles y modalidades de sistema educativo.

Esta ley, a través de su programa nacional de compensación salarial, también contribuyó con la igualación en un piso nacional de los salarios iniciales docentes en aquellas provincias que permanecen bajo esa línea de la escala en los sueldos.

En todos estos años no sólo tuvo una evolución positiva la inversión del Estado Nacional y Provincial en educación ciencia y tecnología, sino que ese aumento constante también puede observarse, incluso con un mayor porcentaje, en el indicador "inversión por alumno". "Entre 2005 y 2012, la inversión por alumno del sector estatal aumentó un $70 \%$ en términos reales y duplicó la que se mantenía a mediados de los noventa". ${ }^{1}$

En los fundamentos del proyecto de ley, elaborado por la Dra. Adriana Puiggrós, se expresa claramente que entre los logros de la Ley 26.075, “se cumplió con el propósito de incluir al 100\% de los niños/as de 5 años de edad y se superó el de escolarizar al 50\% de los niños de 3 y 4 años (en el año 2010 se alcanzó el 54 y el 81,5\% respectivamente)". La legisladora también valora las "estrategias de asignación de recursos mediante programas universales (AUH, Progresar, Conectar igualdad, entre otros) y destinados al compromiso de reducir el rezago educativo (Programa Fines y de capacitación laboral). Se avanzó en el cumplimiento de la capacitación docente y la educación técnica recibió la mayor inversión de la historia. También se crearon más de una decena de nuevas universidades nacionales, incorporando a miles de jóvenes a los estudios superiores, y se fomentó el regreso al país de más de mil investigadores, para lo que también hubo que invertir en infraestructura para el desarrollo de la ciencia y la tecnología".

De todos modos, hay metas más puntuales que no se alcanzaron, o bien, se han alcanzado parcialmente. Es el caso de la cantidad de escuelas con jornada escolar extendida o completa, como así también la cobertura real de la obligatoriedad en los niveles inicial y secundario.

Parte del desfasaje entre el planteo teórico de las metas de la Ley de financiamiento y su efectivo cumplimiento se debe a que dicha ley fue sancionada un año antes de la 
sanción de otra norma muy importante, como fue la Ley de Educación Nacional $\mathrm{n}^{\underline{0}}$ 26.206, en la que se siguieron desplegando y ampliando más derechos en el campo social y educativo. Igualmente, en el proceso de aplicación de la norma se fueron corrigiendo de hecho las inversiones para cumplir, en las medidas de las posibilidades, con los requerimientos legales vigentes.

El reconocimiento del relativo "incumplimiento", más que una crítica, es un primer paso para reabrir el debate hacia la construcción de un nuevo marco legal que regule en financiamiento educativo, no solo para hacer lo que falta, sino para planificar de acuerdo a los nuevos desafíos que se presentan.

\section{Un nuevo Proyecto de Ley de Financiamiento Educativo}

Tal como afirmamos en el punto anterior, hoy podemos ver que la definición de aquel 6\% del PBI fue muy significativa, sin embargo, a la luz de los avances en materia de derechos sociales, y considerando tanto la expansión del sistema educativo como la aspiración a la inclusión plena de la población en el mismo, ese número porcentual necesita ser ampliado y redimensionado.

Es por ello que desde Ctera hemos acompañado la presentación de un proyecto de Ley, que fuera elaborado por la Dra. Adriana Puiggrós luego de haber mantenido sucesivas reuniones con dirigentes de nuestra organización, legisladores, especialistas e investigadores sobre el tema, que analizaron las diversas situaciones, variables e indicadores que hoy necesitan ser tenidos en cuenta a los efectos de su replanteo.

Entre las cuestiones más importantes, este proyecto de ley propone un aumento progresivo de la inversión en educación entre los años 2016 y 2021 hasta llegar al 10\% del PBI. Especificando que de ese total, un $8 \%$ vaya para la educación universal y obligatoria y un $2 \%$ para educación superior, ciencia y tecnología. Todo ello, "con el objetivo de garantizar la igualdad de oportunidades, de acceso al aprendizaje y el conocimiento y apoyar las políticas de mejora en la calidad de la enseñanza, según lo establecido por la Ley no 26.206".

Puntualmente, se propone garantizar la inclusión en el nivel inicial a la totalidad de la población de 4 años de edad y asegurar la universalización del mismo para los niños y niñas desde los 45 días a los 3 años de edad. Como así también garantizar un mínimo de 14 años de escolaridad obligatoria y un 30\% de escuelas de educación básica que brinden jornadas extendidas o completas, especialmente para los sectores sociales y las regiones geográficas más desfavorecidas. Estos planteos de inclusión no solo prevén el acceso al sistema, sino también las estrategias necesarias para sostener la asistencia, permanencia y egreso en los términos planificados por el sistema educativo nacional y provincial. 
La erradicación definitiva del analfabetismo en todos los grupos etarios, la incorporación de las nuevas tecnologías y la conectividad en todas las escuelas, la mejora de las condiciones de enseñanza y de aprendizaje, la enseñanza de una segunda lengua, el fortalecimiento de la escuela técnica y la formación profesional, la inversión en infraestructura y equipamiento, la organización escolar adecuada con máximo de 25 alumnos por curso y la integración de los estudiantes con discapacidad, son algunas de las principales metas que se pretenden alcanzar con el financiamiento. Y uno de los principales puntos que queremos resaltar desde nuestra organización es que el proyecto de ley también plantea: "Mejorar las condiciones laborales y salariales de los docentes de todos los niveles del sistema educativo, la jerarquización de la carrera docentes y el mejoramiento de la calidad en la formación docente". A lo que se suma la consideración de crear los cargos necesarios para cumplir con la cobertura, contemplando no solo el trabajo frente a alumnos, sino también las actividades de índole institucional y otras acciones.

El otro punto importante que plantea este proyecto de ley es la definición de la participación del Gobierno Nacional con el 60\% en el esfuerzo de inversión adicional para el cumplimiento de la Meta de crecimiento anual. En la ley anterior este porcentaje era del $40 \%$ quedando el $60 \%$ a cargo de las provincias lo que generaba mayores condiciones para ampliar las brechas y la desigualdad a nivel país. Con el nuevo proyecto, se invierte la anterior proporción que fijaba 40 \% para Nación y 60 \% para las Provincias.

Este proyecto de ley también reconoce a las organizaciones gremiales, la posibilidad de contar con la información para poder evaluar el funcionamiento del sistema tanto en lo físico como en lo financiero y presupuestario, y verificar el estricto cumplimiento de los compromisos asumidos por el Estado Nacional y provincial según corresponda en cada caso.

\section{Desafíos educativos bajo el gobierno conservador}

Para nuestra organización sindical docente el principal desafío en todo este tiempo sigue siendo lograr la aprobación de una nueva Ley de Financiamiento Educativo que permita alcanzar un conjunto de objetivos que estén definidos desde la perspectiva de la inclusión socio-educativa plena y la constante ampliación del derecho a la educación pública, popular y democrática.

A fines del año 2010, cuando se llegó a la meta global de un 6\% del PBI para la inversión en educación, la Ctera definió la "campaña por una nueva ley de financiamiento" como eje estratégico de la política sindical.

Desde entonces, batallamos por un marco normativo que resguarde lo ya alcanzado y que, a la vez, permita seguir profundizando aquellas políticas educativas que, principalmente, garanticen: 
» Cobertura plena con "educación pública" en aquellos niveles del sistema educativo en los que aún esta meta no se cumple como es el caso de la educación inicial y secundaria, teniendo en cuenta no solo las condiciones de ingreso al sistema y al nivel respectivo, sino también la permanencia y el egreso en las mejores condiciones de enseñanza y de aprendizaje que se pueda brindar, repetimos, con la "educación pública".

" Creación de puestos de trabajo acordes a las necesidades de la extensión del sistema, contemplando una progresiva mutación de horas cátedras a cargos, que, a su vez, incluya no solo el reconocimiento de las horas frente a alumnos, sino también un tiempo suficiente para la formación permanente, la investigación educativa y demás acciones inherentes al trabajo docente.

» Dignificación del salario docente, de las condiciones laborales y del ambiente de trabajo, pugnando por terminar con las desigualdades existentes en las distintas regiones del país.

» Definición de dispositivos pedagógicos democráticos que tiendan a una educación pública de calidad sin caer en los reduccionismos que plantean la "calidad educativa" se alcanza con mecanismos de evaluación estandarizada, externa y punitiva-correccional, enfocándose únicamente en el rendimiento de los alumnos y en el desempeño de los docentes, de manera individual.

» Consolidación del Programa de Formación Permanente y en Ejercicio, poniendo mayor énfasis en las instancias institucionales de formación colectiva, desmontando progresivamente los dispositivos meritocráticos que sólo focalizan al individuo y fomentan la comercialización del conocimiento.

» Continuidad del proceso de estabilidad para los trabajadores de la educación. Generando las instancias concursales democráticas para seguir avanzando más allá de las 370 mil titularizaciones docentes concretadas en todo el país durante los último tres años. Como así también, regularizar la situación de los cargos que se generan como consecuencia de la aplicación de programas nacionales y que permanecen con contratos temporarios generando precarización. Tal es el caso de los trabajadores del plan Fines, las orquestas juveniles, CAI, CAJ, y capacitadores del programa de formación docente permanente, entre otros.

Ahora bien, lo que cambió drásticamente desde la presentación del proyecto de ley a la actualidad es el contexto político y social en el país; como consecuencia de ello, hoy tenemos que la disputa por una nueva ley de financiamiento se da frente a un nuevo Gobierno que clara y aceleradamente se encamina hacia una restauración conservadora. Esto se puede observar en las primeras medidas tomadas que han tendido limitar, 
restringir y ajustar todo lo que signifique condiciones de trabajo dignas y derechos conseguidos por los trabajadores en los últimos años.

Por esto, y hoy más que nunca, tienen vigencia las palabras de nuestra compañera Stella Maldonado cuando afirmaba: "Este proyecto de ley es parte de un programa de lucha", y en el marco de ese plan de lucha, tenemos que estar alertas para redoblar los esfuerzos porque la derecha entiende que la educación es un servicio diferenciado e incluso un campo promisorio para el capital a la hora de hacer negocios.

Es preciso debatir fuertemente para poder profundizar el camino de las transformaciones tal como se venían dando y discutirle a la derecha no sólo los alcances de la ley y el destino de los recursos del financiamiento, sino también y, fundamentalmente, el contenido político y pedagógico de la misma.

Este también es el momento de cuestionar seriamente los sistemas de subsidios a la educación privada que queda en manos de las empresas que operan en el campo educativo; empresas que no sólo buscan obtener ganancias sino que, de fondo, pretenden ganar la batalla cultural que significaría, para ellos, el triunfo definitivo del modo de vida capitalista, colonial y patriarcal.

Hugo Yasky planteaba que "la derecha, los sectores concentrados de poder, mienten con una profunda deshonestidad intelectual; dicen que la educación no mejoró en estos doce años" y esa es la justificación última para dejar el sistema educativo en manos de la iniciativa privada. La deslegitimación de todo lo estatal por lento, ineficiente, y la reivindicación de todo lo que sea privado.

Nosotros nos oponemos a esto, y peleamos por una ley nacional que garantice el Financiamiento del Estado para una educación pública de calidad, para una sociedad justa, libre y soberana.

Recibido en abril de 2016 y aprobado en junio de 2016

\section{Notas}

1 Afirmación tomada del informe del Documento de Políticas Públicas, Análisis 135, elaborado por el CIPPEC, en junio de 2014, acerca del cumplimiento de la Ley de financiamiento Educativo.

2 Ibidem. 


\section{Referencias}

Botinelli L. y Sleiman C. (2015). Educación privada, aportes para la discusión sobre las subvenciones públicas, Cuadernillos "Sociales en Debate" nำ, UBA.

Duhalde Miguel (2016). Presupuesto Educativo: qué hay, qué falta, Ediciones CTERA, Serie "Pedagogía y Políticas Educativas", Buenos Aires, pp 22-28

Feldfeber, M. -comp- (2003). Los sentidos de lo público: reflexiones desde el campo educativo. ¿Existe un espacio público no estatal? Buenos Aires: Novedades Educativas, 2003.

Feldfeber, M. (2011). “¿Es pública la escuela privada? Notas para pensar en el Estado y en la educación". En Mapas y recorridos de la educación de gestión privada en la Argentina. Perazza, R. (coord.). Buenos Aires, Aique Grupo Editor.

Gluz N. y Feldfeber M. (2009). “Las políticas educativas en la Argentina: Herencias de los 90, contradicciones y tendencias de nuevo signo", Educação e Sociedade, Campinas, v. 32, n. 115, p. 339356, abr.-jun. 2011.

INDEC (Instituto Nacional de Estadística y Censo). Encuesta permanente de hogares, Informe 2001, 2005, 2010.

Ministerio de Educación $(2008,2010)$. Relevamiento anuales de la Dirección Nacional de Información y Evaluación dela Calidad Educativa.

Morduchowicz, A. y G. Iglesias (2011). "Auge y avance de los subsidios estatales al financiamiento de las escuelas privadas en la Argentina". En Mapas y recorridos de la educación de gestión privada en la Argentina. Perazza, R. (coord.). Buenos Aires, Aique Grupo Editor.

Puiggrós Adriana (2016). Ley de Financiamiento Educativo o Leyes del mercado, Ediciones CTERA, Serie "Pedagogía y Políticas Educativas", Buenos Aires, pp 10-17

Puiggrós Adriana (1990), Historia de la Educación en la Argentina, Editorial Galerna, Bs. As.

Yasky Hugo (2016). Financiamiento Educativo. Una Lucha histórica de la CTERA, Ediciones CTERA, Serie “Pedagogía y Políticas Educativas", Buenos Aires, pp 6-9. 


\section{The law on the funding of education An historical struggle in Argentina}

ABSTRACT: The article presents a series of analyses focused on the scope of the law that took effect ten years ago; the characteristics and central plans of the new project; and the challenges for the Confederation of Education Workers of Argentina (CTERA) in the context of the country's national project under the guidelines of the conservative restoration.

Keywords: Education financing law. New educational project. The conservative restoration in education.

\section{La loi de financement de l'éducation Une lutte historique en Argentine}

RÉSUMÉ: L'article présente une série d'analyses centrées sur la portée de la loi en vigueur depuis maintenant 10 ans; les carcactéristiques et les propositions du nouveau projet et les défis de la Confédération des Travailleurs de l'Education de la République Argentine ( Ctera) dans le contexte d'un projet national régi par les lignes directrives d'un retour du conservatisme.

Mots-clés: Loi de financement éducatif. Nouveau projet éducatif. Retour conservateur en éducation.

\section{A lei de financiamento educacional Na Argentina, uma luta histórica}

RESUMO: O artigo apresenta uma série de análises com enfoque nas conquistas da lei vigente nos últimos dez anos, nas características e propostas centrais do novo projeto e nos desafios da Confederação de Trabalhadores da Educação da República Argentina (CTERA) no contexto de um projeto de país governado sob as diretrizes da restauração conservadora.

Palavras-chave: Lei de financiamento educacional. Novo projeto educacional. Restauração conservadora na educação. 